\title{
Thomas Willis: the first paediatric neurologist?
}

\author{
A N Williams, R Sunderland
}

St Nicolas Park Clinic, North Warwickshire NHS Trust,

Windermere Avenue, Nuneaton CV11 6HH, UK

A N Williams

\section{Birmingham}

Children's Hospital,

Steelhouse Lane,

Birmingham B4 6NU,

UK

R Sunderland

Correspondence to: Dr Williams awilliams@nw-tr.wmids.nhs.uk

Accepted 18 July 2001

\section{Thomas Willis-the man and doctor} Thomas Willis (1621-75) the man (fig 1) is often overshadowed by his medical discoveries. He was born on a Wiltshire farm and took his MA from Christchurch College, Oxford in 1642. He was an ardent Royalist and enlisted "as a Souldier in the University Legion"-an auxiliary regiment-serving two years in the civil war. When Oxford surrendered in June 1646, all the Royalist soldiers were ordered to leave the city. But Willis returned by the beginning of the next academic term, graduating and being licensed to practice on 8 December 1646 . Because of the wartime conditions, his medical training was probably less than six months. In this he was fortunate as it allowed him to read more widely and be aware of new ideas. ${ }^{1}$

Willis slowly established what was to become a lucrative medical practice enhanced by the

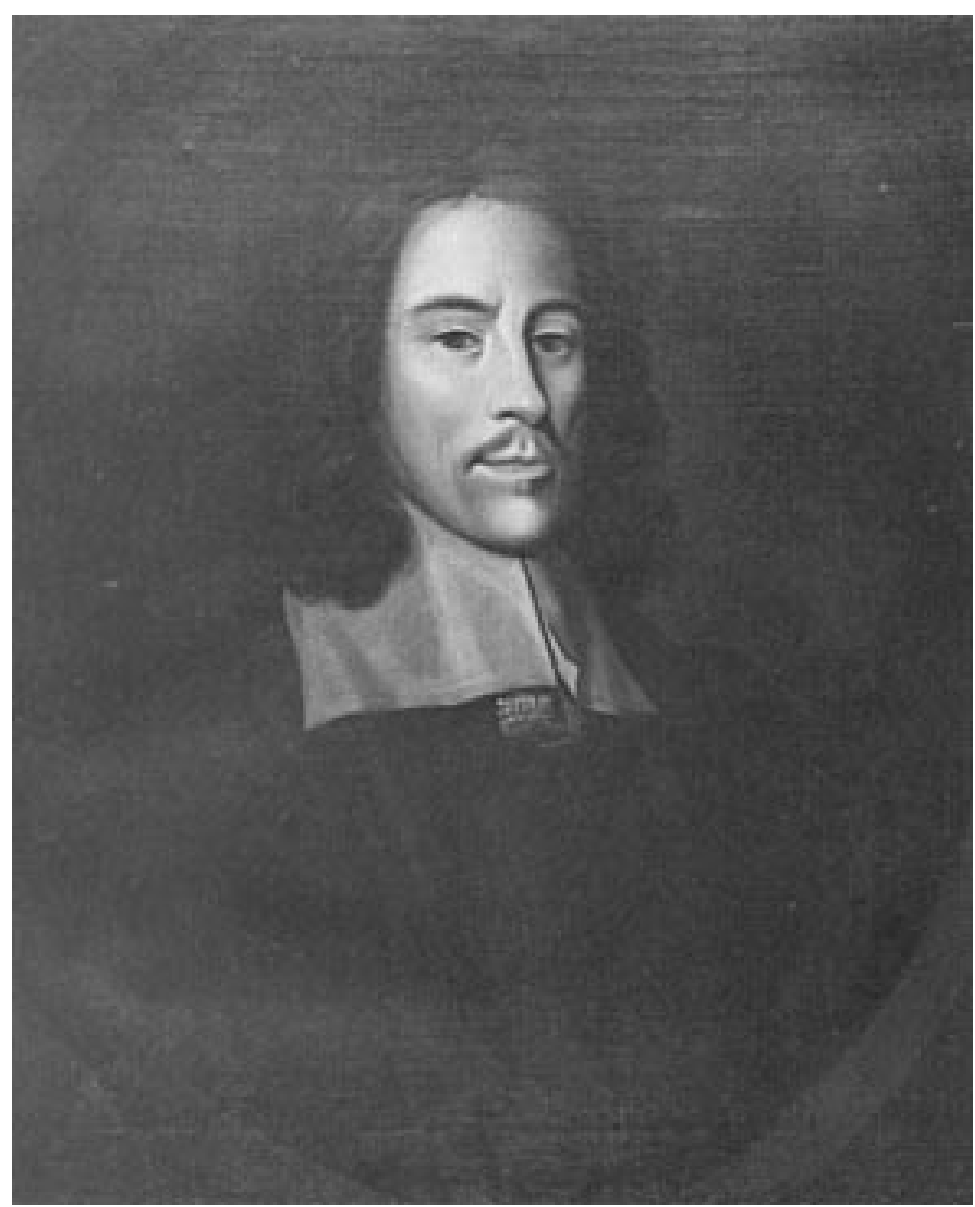

Figure 1 Thomas Willis. With permission from the Bodleian Library, University of Oxford.

spectacular "resurrection" of Anne Green, who had been hanged in 1650 for infanticide. ${ }^{2} \mathrm{He}$ was one of a small scientific group with Royalist sympathies including Boyle, Wren, and Hooke. After the Restoration, this group moved to London and formed the Royal Society. Willis employed Robert Hooke who subsequently developed the microscope and the first artificial ventilator, and suggested to Newton the inverse square law of gravitation. His Cerebri Anatome (1664) - a classical account of the nervous system - was illustrated by Christopher Wren.

In 1660 Willis was appointed Sedleian Professor of Natural Philosophy at Oxford. There he lived in Beam Hall, Merton Street, opposite Merton College Lodge. He had four sons and four daughters, and all but the eldest son predeceased him. He was devastated by the death of his wife Mary in 1666. Later that year he was invited to London by the Archbishop of Canterbury where he continued his lucrative practice.

He was noted for his direct speaking, irrespective of the station of his patient. One hostile contemporary account puts it more directly, describing him as "a Plain Man, a Man of no Carriage, little Discourse, Complaisance or Society". ${ }^{3}$ When Charles II, a noted procreator, consulted Willis regarding his wife's infertility, he was not consulted again. In spite of being a Royal appointee, Willis's bedside manner did not meet with Royal approval.

In his lifetime and posthumously, Willis's reputation has been subjected to unsubstantiated attacks regarding his integrity. His contemporary attacks might well have driven by envy (he was the wealthiest doctor in Oxford). Willis died of pleurisy in 1675 and is buried in Westminster Abbey.

\section{Willis the neurologist}

Willis is credited with creating the word neurologie, ${ }^{45}$ and is rightly remembered primarily for his astute observations of neurological conditions. But it is often forgotten that he made significant original contributions to pathology, anatomy, cardiology, endocrinology, and gastroenterology. ${ }^{4}$ Willis is especially remembered by medical students for "the circle of Willis", the arterial anastomosis at the base of the brain. Although this had already been described by Wepfer, Willis is credited with explaining the functional significance of this anastomosis as a safety device against occlusive deficiency. He confirmed this by elegant postmortem dye studies. ${ }^{16}$ 
The first paediatric neurologist

Re-reading the work of this medical forefather leads to an appreciation of his significant contributions to the development of paediatric neurology, since in his practice and teaching he laid the foundations for modern practice.

Presented here are a few extracts from his work to support this claim and which give an interesting insight into the practice of the seventeenth century physician. They illustrate how, long before modern diagnostic aids, Willis's application of astute history taking and clinical observation lead to a diagnosis. Willis's work was published in Latin. The available translations are not usually by medical authors and are well recognised as having limitations. ${ }^{7}$ Because of the incomplete nature of the translations, with omissions of key cases, we have principally used two editions of Portage's contemporary translation. ${ }^{89}$

CASE 1: INTRACRANIAL EFFUSION IN INFANCY Willis illustrates the difficulty in determining causes of neurological impairment. In the following discussion on convulsions in children, he recognises the importance of necropsy to provide a greater understanding of the underlying diagnosis: a principle that might be remembered today.

I have opened the dead bodies of many, which this disease had oppressed: I have allways in vain sought the cause, within the viscera and first passage of concoction: in the heads of many, as serous water being heaped up, within the Cavity, under the Cerebel, and distending the membrane, which clothes the oblong pith or marrow, did over flow the beginnings of the nerves: in some no footsteps of this disease appeared: so that, what sticking to the spirits did irritate them into explosions, was of so inperceivable a bulk and its original so altogether hid, that it could not be found out by the most perspicacious scrutiny of the sight.

The description of intracerebral serous fluid distending the membrane under the cerebel is consistent with the modern description of chronic subdural effusion. The possible causes would include birth injury, coagulation disorders (especially vitamin $\mathrm{K}$ deficiency), sterile effusion following meningitis, and metabolic disorders. In current practice suspicions of a non-accidental shaking injury would also be raised, which is more clearly illustrated by the following case.

CASE 2: CONVULSIONS CAUSED BY PROBABLE WHIPLASH SHAKING INJURY

Sometime past in this City, many children of a certain woman dyed of the Dysease, at length the forth as the others dyed within the month: we dissected the Head and here no serous colluvies or water did over flow the ventricle, but only the substance of the Brain and it appendix was myster than ordinary, and looser: what was most worthy of observation was, that in the Cavity which lyes under the Cerebel upon the trunk of the oblong pith, we found a remarkable heap of clotter'd and as it were concerted blood. ${ }^{9}$

Willis presents the clinical history and postmortem findings of the fourth child of a mother who had already lost three children with fatal neonatal convulsions. The description of clotted blood, a moist brain substance without a collection of fluid under the cerebral membranes, is consistent with an acute subdural haematoma. Viewed from our present understanding of medical knowledge, the possibility of an inherited coagulopathy affecting all four children is most unlikely. Although poor obstetric practice may have been the cause, Willis makes no reference to accoucheurs.

The possibility of series of shaken babies must be considered. ${ }^{10}$ This is reinforced by the subsequent history of this family which was recorded by John Locke, one of Willis's medical students. Locke attended Willis's medical lectures in Oxford and his notes are in the Bodleian Library, Oxford. ${ }^{11}{ }^{12}$ Locke recorded a similar description of this case and relates that Willis attended three subsequent births to this mother, all of whom were bled by him immediately after birth by the incision of a fontanelle into the neck, and the application of leeches behind the ears. These children did not develop convulsions and were all subsequently well. ${ }^{13}$ There is no record of any change in the obstetric care.

The above case history, the postmortem findings, and the dramatic change in outcome after what we now know to be a medically ineffectual treatment, suggest that the four children died of whiplash shaking injury. ${ }^{10}$

\section{CASE 3: CHRONIC HEADACHE}

Willis wrote an extensive treatise entitled "Instructions and Prescripts for the Cure Head-Ach", from which the next three cases are taken. ${ }^{14}$

Chronic headache is a common presentation to modern doctors, with parents especially worrying about space occupying lesions. Willis does not despair about the management of this problem. He offers practical advice and reassurance of chronic headache in childhood:

But though a continual head-ach (especially if it be drawn in length for many weeks without intermissions) be not without danger, nevertheless we must presently not despair of its Cure, because the cause of this however fixed and immovable soever it may seem, is often cured by a long use of remedies-nay sometimes by Time and Nature: though in a case that is almost desperate there is need of some physick. ${ }^{14}$

\section{CASE 4: VENOUS INFARCTION}

Willis describes a case of fatal headache caused by venous infarction, possibly precipitated by septic thrombosis of the vein of Galen or the straight sinus. ${ }^{15}$

... sometimes mortal and incurable headaches arise from a phlegmon and abscess. A while since a University scholar, after he had complained for a fortnight of a very great headach, afflicting him almost constantly: at length the fever becoming stronger, presently watchings, convulsive motions and a talking light headedness ensued: at which time a physician being called, blooding, clysters, plasters, revulsives, vesicatories, also inward remedies for withdrawing the course of the blood and humours from the head, being carefully administered, he could do no good, but death in a short time followed. The scull being opened, the vessels spread over the meninges were filled with blood, and very much distended, as tho the whole mass of blood had flown thither: so that the sinus being dissected and opened, above half a pound of blood flowed forth. Moreover the membranes themselves being affected throughout 
with a phlegmonous tumour, appeared discoloured: these coverings being taken away, all the anfractus of the brain, and its ventricles were full of clear water: and its substance being too much irrigated, was moist throughout, and nothing firm: For the blood being heaped there together when it could not circulate, threw off from itself a plenty of serum, by which the whole head was soon floated: so that the disease, curable haply at the beginning by phlebotomy, afterward became mortal.

CASE 5: CEREBRAL ABSCESS

Willis recognised the difference between chronic symptoms without signs in the following description of fatal cerebral abscess.

... so sometimes mortal and incurable headaches arise from a phlegmon and abscess: ... I remember another University scholar, who after being constantly and very sorely afflicted with a hemicrania under the temporal suture for three weeks, fell at last into a fatal apoplexy. The head being opened, a phlegmon had grown in the meninges near the place paining, from which at length suppurated and broken, the sanies (sanies equals corrupted body matter, thin feted pus) falling on the brain, had affected its substance, with a lividness and corruption. ${ }^{14}$

This description is clinically consistent with a ruptured cerebral abscess, possibly secondary to chronic middle ear or bone infection.

\section{CASE 6: TUBERCULOSIS}

The following case provides a fascinating mixture of symptoms and evolution of clinical signs.

A person whose children dyed all of convulsions within three months time, at length to prevent the like fatal accident in a child fresh born, sought for remedies.

Willis prescribed leeches and bleeding (up to two ounces) as well medicines to be given during specific stages of the solar and lunar cycles.

The infant continued well for about four months but then began to be troubled with convulsive effects.

Willis increased the dose of both bleeding and leeches and had them also applied to the child's nurse.

Within two or three days the child grew well. Afterwards when within four or five months, the convulsions wheturned at times, still by the use of the same remedies returned at times, still by the use of the same remedies he was cur'd. After a year and a half the convulsive affects wholly ceast, but about the lower part of the backbone a tumour without pain grew up, whence some Crookedness of the Vertebrae and a weakness of the leggs and at length a palsy were caused. It seems in this case that the convulsive matter, which was wont to assail the Origines of the nerves, at length entering the Spinal Marrow, and being thrown down into its lower part, wholly stopt the mouths of the Arteries belonging to it: to wit, because to the explosive Particles, other narcotick

and grosser Particles had join'd themselves ....8

The tragic history of repeated familial convulsions has certain features in common with those described in case 2 above. The possibility of polycythaemia neonatorum could also be considered. This condition is still today treated by bleeding (now termed exchange transfusion). The subsequent development of a lower spinal tumour with paraparesis suggests one of the commoner childhood malignancies or a tuberculous abscess. We are unclear as to the benefits which were derived from treating the nurse. We wonder whether she may have had symptoms such as a chronic cough and was the primary focus in this family.

CASE 7: EPILEPSY

Willis wrote extensively about this condition which still provides its medical challenges. $\mathrm{He}$ succinctly described a management strategy not unfamiliar to today's physicians. ${ }^{8}$

Concerning the cure of the falling sickness the indications are either Curatory, having regard to the Fit, and either keep it off as it is coming or soon force it off when it has ceiz'd: Or they are Prophylactick, and regard the cause of the Disease, which if they remove, its accesses will be kept off for the future.

For neonatal convulsions Willis recommended:

The convulsive fits are excellently provided against if presently after a child is born an issue be made in the nucha, and blood be drawn from the jugular veins by leeches. For by the former, the corruptions of the nervous juice are conveyed away and by the latter the impure efforeficiencies of the blood are withdrawn from the head. ${ }^{8}$

The effect of puberty on epileptic seizures was noted by Willis. He also recognised that many epileptics "grow out" of the disease (consistent with the current observation that for every one adult with epilepsy there are seven children).

It is observed that sometimes the epilepsy terminates of its own accord, viz about the time of puberty, so that those who are not cur'd before that period is past, viz their twenty fifth year, scarce ever recover their health; for about the time of puberty a double alteration happens to the humane body, and often a release from the epilepsy or any other disease more deeply routed.

In modern paediatric practice, puberty is usually completed by the 15 th year, although in deprived communities the onset may be delayed. It is therefore of interest that 350 years ago Willis allowed until the 25th year before considering epilepsy to be permanent.

CASE 8: PSEUDOSEIZURES?

Willis recognised that epilepsy can manifest during the times of rapid growth, especially during adolescence, and may also be aggravated by hormonal changes, which occur during the menstrual cycle.

The daughter of an ale house keeper at Oxford had been very subject from her infancy to a Catarrh falling on her eyes, being otherwise strong and sound enough, she lived also daily us'd to hard labour: about the fourteenth year of her age she began to be ceased with fits of the epilepsy, where of she underwent many, they chiefly following her according to the greater changes of the moon: Being entreated to endeavour her recovery, I gave her a vomit of the Solar Precipitate, and advised her to repeat the same three days before every new and full moon, and likewise at every time four days after the vomit taken, she should take twice a day a dram of powder from the roots of Male Peony, with a draft of black Cherry water: By these remedies the fits intermitted so long that she seem'd to be cured. When afterward they return'd again she was again recovered by the use of the same Medicines: and then her menses happening to flow, and keeping their due course, she continued for the time to come free of that disease.

The resolution of this young lady's convulsions by induced vomiting and crushed peony roots 
with black cherry water, however, suggests a psychogenic cause quite possibly related to the distresses or abuses of living and working in an Oxford ale house during adolescence. ${ }^{16}$

CASE 9: MYALGIC ENCEPHALOPATHY MERGING INTO ANOREXIA NERVOSA.

Willis writes of an "epidemick fever", that occurred in 1661, "reigning chiefly among children and young people ... wont to afflict them with a long and as it were chronical sickness." Willis emphasised that there was no accompanying change in body temperature.

\section{a great weakness in the whole body with languor of the spirits and deadness of the Anima Functions.}

Willis adds that there is no appetite but no vomiting.

The diseased being indisposed to all motion, sought only to lye on a bed and do nothing, within a short time, and sometimes from the first invasion of the disease, they complained of great giddiness, a ringing in the ears, and often turbulent motion and great perturbation in the brain; which sort of symptoms were usually accounted a pathognomick sign as it were of the sudden approach of this disease ... But continuing for many weeks and sometimes months, it brought the diseas'd into a mighty atropia, and often cast them into an incurable consumption. ... For I have frequently observed in many children and often on women, after seven or eight days that they have wholly lost both sense and speech so that they have lain for some time, sometimes for whole months space, without knowing persons present, and their excrements passing from them after an insensible manner: and if the use of their judgement and reason in some measure held, yet they were troubled with a frequent delirium, and always talk's light-headed in their sleep. ${ }^{8}$

Within this series of cases Willis describes a nurse's management of an 11 year old boy by blistering and emetics with fatal outcome. At this distance of time, the possibility of some encephalopathic process cannot be excluded, yet Willis is clear none of these patients had any fever at any time.

\section{Conclusion}

We have briefly summarised a selection of cases from Willis's writings, illustrating his involvement with children and adolescents. The detailed case histories, recording of clinical evidence, and accompanying postmortem examinations provide a fascinating window into seventeenth century medicine and child health practices. Whatever their efficacy, Willis's detailed recording of the effects left a corpus of information for succeeding generations to implement the successful and avoid the unsuccessful.

Although this selection represents a small fraction of Willis's caseload, it illustrates his experience of the wide variety of aetiologies that are embraced within modern paediatric neurology. In the intervening three centuries, a wide range of child health services including general, community, paediatric neurology, and psychology have been born. Willis may never have imagined the advances in diagnostic or therapeutic potential that have occurred up to our present time. Although undoubtedly a great man, we believe that this particular contribution has not been fully acknowledged. We propose that Willis be recognised as the first paediatric neurologist (even if he would not have recognised the term).

We would like to acknowledge Professor A Moritz and Mr HJR Wing for their assistance and advice in certain parts of this paper.

1 Dewhurst K. Thomas Willis and the foundations of British neurology. In: Rose FC and Bynum WF, eds. Historical
aspects of the neurosciences. New York: Raven Press, aspects of the

2 Hughes JT. Miraculous deliverance of Anne Green: an Oxford case of resuscitation in the seventeenth century. BMF 1982;285:1792-3.

3 Wood A. Athenae Oxonienses, Vol 2, 2nd edn, 1721:549 (quoted in Dewhurst K. Thomas Willis and the foundations of British neurology. In: Rose FC and Bynum WF, eds. Historical aspects of the neurosciences. New York: Raven Press, 1982:329).

4 Hughes JT. Pioneers in neurology: Thomas Willis (16211675). F Neurol 2000;247:151-2.

5 Jay V. The legacy of Thomas Willis. Childs Nerv Syst 1998; 14:92-3.

6 Isler H. Thomas Willis 1621-1675. Doctor and scientist. New York, London: Hafner Publishing Company, 1968:104.

7 Isler H. The origins of neurology in the 17 th century. In: Rose FC, ed. Neuroscience across the centuries. London: Smith Gordon, 1989:79-94.

8 Willis T. The London Practice of Physick: or the whole practical part of physick. Printed for Thomas Basset and William Cooke, London, 1685:238-55,273-4.

9 Willis T. An essay of the pathology of the brain and nervous stock in which convulsive disease are treated of. Translated by Samuel Portage, printed by JBT Dring, London, 1681: $25-6$.

10 Williams AN. Thomas Willis, neonatal convulsions, childhood stroke and infanticide in seventeenth century England. In press.

11 Dewhurst K. Willis's Oxford lectures. Oxford: Sandford Publications, $1980: \mathrm{ix}-\mathrm{x}$.

12 Bodleian Library. Ms Locke f 19 , pp 48-50.

13 Dewhurst K. Willis's Oxford lectures. Oxford: Sandford Publications, 1980:86.

14 Willis T. The London Practice of Physick: or the whole practical part of physick. Printed for Thomas Basset and William Cooke, London, 1685:370-85.

15 Hughes JT. Thomas Willis: the first Oxford neuropathologist. In: Rose FC, ed. Neuroscience across the centuries. London: Smith-Gordon, 1989:93-4.

16 Radbill SX. Children in a world of violence. A history of child abuse. In: Helfer RE, ed. The battered child, 3rd edn. Chicago: University of Chicago Press, 1999:9. 